\title{
Effects of Radiation on Oral Tissues
}

\author{
Karpaga Preethitha .S
}

\begin{abstract}
Cancer is a term used for diseases in which abnormal cells divide without control and are able to invade other tissues. There are more than 100 different types of cancer (1). Cancer is the second most common disease in India responsible for maximum mortality with about 0.3 million deaths per year (2). Radiotherapy is a treatment that involves the use of high energy radiation, commonly used for the treatment of cancer (3). It works by damaging the genes (DNA) in cells. When the gene of the cancer cells is damaged, it can't grow or divide anymore. Overtime the cancer cell dies(4). Oral cancer is a deadly disease and if left untreated it will grow fast, destroys the orofacial structures and ultimately leads to the death of the patient. India stands first in the incidence of oral cancer as it is recorded that out of the total number of cancers in the different parts of the body $40 \%$ of the cancers are oral cancers.
\end{abstract}

Keywords: Cancer, High Mortality, High Energy Radiation

\section{Introduction}

Oral cancer can be defined as "malignant tumor of dysplastic cells of oral tissues both from epithelium and connective tissue". Oral cancer that develops from epithelium is called carcinoma and that which develops from connective tissue is called sarcoma.

When the oral cavity and salivary glands are exposed to high doses of radiation, clinical consequences including hyposalivation, mucositis, taste loss, trismus, and osteoradionecrosis should be regarded as the most common side-effects. Mucositis and taste loss are reversible consequences, usually subsiding early post-irradiation, whereas hyposalivation is commonly irreversible. Additionally, the risk of rampant tooth decay with its sudden onset and osteonecrosis is a lifelong threat. Thus, early, active participation of the dental profession in the development of preventive and therapeutic strategies, and in the education and rehabilitation of patients is paramount in consideration of quality-of-life issues during and after radiotherapy. (5)

\section{Xerostomia:}

Xerostomia is defined as dry mouth resulting from reduced or absent saliva flow (6). Xerostomia (dry mouth) is one of the serious complications of head and neck irradiation and has a strong influence on a patient's activities of daily living. (7). It is due to irreparable damage is caused to the salivary glands

\section{Pathophysiology:}

The concept of granulation hypothesis suggests that the membrane of secreting granular acinar cells become damaged by radiation-induced lipid peroxidation, and consequently proteolytic enzymes begin to leak from these granules, causing immediate lysis of the cells.

First, there is a defect in cellular functioning because of selective membrane damage, confounding the receptor mediated signaling pathways of water excretion. No immediate cell death or lysis takes place. Late damage is explained by classical cell killing of the progenitor cells and stem cells, thus inhibiting proper cell renewal and damage to the cellular environment, causing a shortage of properly functioning secretory cells. (8).

\section{Mucositis:}

The term oral Mucositis emerged in late 1980s to describe the adverse effects of chemotherapy and radiotherapy induced inflammation of the oral mucosa. Mucositis is one of the most common adverse reactions encountered in radiation therapy of head and neck cancers. Patients receiving radiation, in particular to head and neck cancers, have a $30 \%$ to $60 \%$ chance. (9)

\section{Pathophysiology:}

Mucositis, which can be caused by radiation or chemotherapy, results from the mitotic death of the basal cells of the mucosal epithelium. Portions of the gastrointestinal tract become inflamed, and red, burn-like or ulcer-like sores appear throughout the mouth (10). It occurs in 4 stages: - initial inflammatory or vascular stage, epithelial stage, ulcerative stage, healing stage.

\section{Radiation caries:}

The risk of acquiring caries increases in patients receiving radiation therapy. The risk increases secondary to a number of factors including shifts to a cariogenic flora, reduced concentrations of salivary antimicrobial proteins, and loss of mineralizing components (11).

\section{Pathophysiology:}

Radiation therapy does not directly cause caries, it is the alterations in the oral cavity that occurs due to treatment that leads to radiation caries. Saliva helps maintain a healthy balance of bacteria in the mouth. Without enough saliva, the bacteria and other organisms in the mouth grow too quickly, causing dental decay(12). Demineralization of the teeth and the breakdown of tooth structure can also occur as a result of treatment. This is not necessarily the result of the teeth being in the direct field of radiation therapy. Demineralization may also result when the parotid and/or submandibular/ sublingual salivary glands are included in the field of radiation, and are damaged. (10).

\section{Osteoradionecrosis:}

The most important complication of radiotherapy is osteoradionecrosis, which manifests as an area of exposed necrotic bone in the maxillae or mandible that fails to heal during at least three months. In most cases osteoradionecrosis gradually progresses, becoming more extensive and painful, and its late manifestations comprise infection and pathological fracture (13).ORN remains latent 


\section{International Journal of Science and Research (IJSR) \\ ISSN (Online): 2319-7064 \\ Index Copernicus Value (2015): 78.96 | Impact Factor (2015): 6.391}

and without symptoms until the lesions are visually detected or the patient begins to experience discomfort, with denuded bone, pain,swelling, suppuration and the formation of a cutaneousfistula or pathological fracture(14).

\section{Pathophysiology:}

The most prominent etiologic factor is the effect of radiation on the endothelial lining of the vessels resulting in hypocellularity, vascularitis followed by obliterate endarteritis, ischemia, fistula and pathologic fracture of the bone (15). It is the result of hypoxic, hypovascular, hypocellular tissue followed by tissue breakdown leading to non healing wound (16).

\section{Infections:}

Bacteria and fungi can live in the mouth, and may develop into an infection when the immune system is not working well, or when white blood cell counts are low. Both of these factors can be caused by the radiation therapy (10).

Bacterial: Gram-positive organisms, including viridans streptococci and Enterococci species, are associated with systemic infection of oral origin. In addition, gram-negative pathogens, including Pseudomonas aeruginosa, Neisseria species, and Escherichia coli, remain of concern. (11)

Fungal: Candida, (Candida albicans) is a fungal disease. The outbreaks of acute episodes where these fungi "bloom and take over" are not due to a change in the fungi, (they are with us all the time in limited numbers) but due to a change in the hosts' immunologic defense mechanisms. Someone who is compromised by radiation treatments, antibiotic therapy, AIDS/HIV, corticosteroid treatment etc. has a lowered ability to keep them in check, and is a prime candidate to have an outbreak of Candida.(10). Recently infections with species of Aspergillus, Mucormycosis, and Rhizopus are also seen increasingly (11).

Viral: infection with herpes group of viruses such as Herpes simplex virus, Varicella-zoster virus, Cytomegalovirus, Epstein-Barr virus are commonly seen in patients undergoing radiation therapy. The non-herpes viruses that can cause infection of oral cavity are adenovirus and oral human papilloma virus (HPV) (11).

\section{References}

[1] http://www.cancer.gov/cancertopics/cancerlibrary/whatis-cancer

[2] Imran Ali, Waseem A Wani, Kishwar Saleem, Correspondence Cancer Therapy 01/2011; 8(8):56-70

[3] www.nhs.uk

[4] www.cancer.org

[5] THE LANCET ONCOLOGY, Volume 7, Issue 4, April 2006, Pages 326-335

[6] http://www.oralcancerfoundation.org/complications/xer ostomia.php\#sthash.Sd7iH1Ud.dpuf

[7] http://www.ajnr.org/content/30/1/53

[8] Piet dirix MD, Sandra Nuyts MD, PhD and Walter Van den Bogaert MD, PhD. Article published online: 31 Oct 2006 DOI: $10.1002 / \mathrm{cncr} .22302$

[9] MaddireddyUmameshwarRao Naidu, GogulaVenkatRamana and Priyadarshini Roy Neoplasia. Sep 2004; 6(5):423-431.
[10] www.oralcancerfoundation.org

[11] www.cancer.gov

[12] www.cancer.net

[13] Journal section: Oral Medicine and Pathology; Med Oral Patol Oral Cir Bucal. 2011 Nov 1;16 (7):e900-4. doi:10.4317/medoral.17257 http://dx.doi.org/doi:10.4317/medoral.17257

[14] Pitak-Arnnop P, Sader R, Dhanuthai K, Masaratana P, Bertolus C, Chaine A, et al. Management of osteoradionecrosis of the jaws: an analysis of evidence. Eur J Surg Oncol.2008; 34:1123-34.

[15] Westernmark A, Sindet-Pedersen S, Jesen J, osteoradionecrosis pathogenesis, treatment and prevention. Tandlaegeblet 1990;94:669-73

[16] SS. Pagare, Sukhjinderkaurkhosa, osteoradionecrosis, 10.5005/jp-journals-10001-1043 